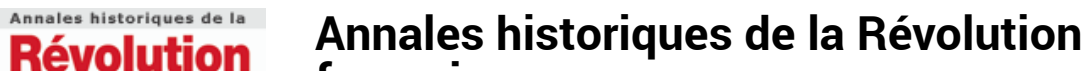

française française

347 | janvier-mars 2007

Varia

\section{Marie-Antoinette, une reine brisée}

Jean-Christian Petitfils

\section{OpenEdition}

Journals

Édition électronique

URL : https://journals.openedition.org/ahrf/8683

DOI : 10.4000/ahrf.8683

ISSN : 1952-403X

Éditeur :

Armand Colin, Société des études robespierristes

Édition imprimée

Date de publication : 1 mars 2007

Pagination : 181-183

ISSN : 0003-4436

\section{Référence électronique}

Jean-Christian Petitfils, « Marie-Antoinette, une reine brisée », Annales historiques de la Révolution

française [En ligne], 347 | janvier-mars 2007, mis en ligne le 21 juillet 2008, consulté le 22 avril 2022.

URL : http://journals.openedition.org/ahrf/8683 ; DOI : https://doi.org/10.4000/ahrf.8683

Ce document a été généré automatiquement le 22 avril 2022.

Tous droits réservés 


\title{
Marie-Antoinette, une reine brisée
}

\author{
Jean-Christian Petitfils
}

\section{RÉFÉRENCE}

Annie Duprat, Marie-Antoinette, une reine brisée, Paris, Perrin, 2006, 286 p., ISBN

2-262-02409-X, $17.90 €$

1 Membre du Centre d'histoire culturelle des sociétés contemporaines de l'Université de Versailles-Saint-Quentin-en-Yvelines, spécialiste du rôle des images et des caricatures, Annie Duprat est l'auteur d'une étude sur Le roi décapité. Essai sur les imaginaires politiques (Cerf, 1992), d'une Histoire de France par la caricature (Larousse, 1999) et d'un livre sur Les rois de papier, la caricature d'Henri III à Louis XVI (Belin, 2002). Avec son dernier ouvrage, Marie-Antoinette, une reine brisée, elle nous présente un modèle original de ce qu'on pourrait appeler un exercice de biographie comparée. Comparée à qui? Tout simplement au propre double de la dernière reine de l'Ancien Régime, ce double noir et monstrueux, issu de l'imaginaire de l'opinion publique avant et pendant la Révolution.

2 Aucune souveraine - et sans doute aucune femme, ajoute l'historienne - n'a été la cible d'autant de critiques fantasmatiques, en paroles, en chansons, en images et en textes. Chantal Thomas, dans La reine scélérate (1989) avait déjà montré jusqu'où pouvait aller ce délire vertigineux. Pamphlets clandestins, journaux vendus sous le manteau, libelles, gazettes à scandale et caricatures se sont déchaînés contre elle avec une rare violence, la violence des mots et des images qui tuent.

3 L'ouvrage, au lieu de se présenter comme une biographie classique avec son déroulement chronologique, prend le parti de présenter un portait kaléidoscopique de la reine. La figure de Marie-Antoinette, en effet, est malaisée à saisir. Quel personnage choisir : l'adolescente timide et rétive qui arrive à la cour en mai 1770 pour épouser le dauphin, Louis Auguste, petit-fils de Louis XV; la reine élégante et brillante, mais étourdie et imprudente, qui s'épanouit à Versailles; la femme avide d'intimité qui se réfugie à Trianon; la mère, pleine de tendresse pour ses enfants, la "tête à vent " (comme la surnommait son frère Joseph II) qui entre en politique, pour son plus grand 
malheur et celui de sa famille, ou la veuve digne et courageuse qui gravit les dernières marches de l'échafaud? Antoinette semble insaisissable.

4 L'approche de l'auteur consiste à décliner en sept tableaux sa descente aux Enfers accompagnée de son implacable double, qui va lui coller à la peau comme une tunique de Nessus : l'Autrichienne, la reine de la mode, le corps de la reine, la Messaline royale, la femme de pouvoir, Madame Veto et la veuve Capet. Ce sont les sept morts de la reine.

On saura gré à Annie Duprat d'avoir montré avec insistance et clairvoyance - après les travaux de l'historien américain Thomas E. Kaiser, parus en 2000 et 2003 dans les revues French History et French Historical Studies - que l'une des causes principales de son impopularité tient à sa propre origine. Le mariage de la fille des Habsbourg-Lorraine avec l'héritier des Bourbons de France était un acte éminemment politique. Il visait à consolider les traités d'alliances de 1756, 1757 et 1759, œuvres de l'abbé de Bernis et du duc de Choiseul. Or, cette fameuse alliance, en rupture complète avec la politique traditionnelle de la France, celle de Richelieu et de Mazarin, jouissait dans l'opinion publique d'une exécration profonde, s'expliquant largement par les défaites de la guerre de Sept Ans et l'humiliant traité de Paris de 1763. L'abbé Jean-Louis Soulavie, historien souvent décrié, mais dont les travaux ont été récemment réévalués, soutenait même, dans ses Mémoires historiques et politiques du règne de Louis XVI (1801), que ce renversement des alliances avait été l'une des causes de la Révolution.

6 Rien d'étonnant dès lors à ce que la haine invétérée de l'Autriche et de l'empire germanique se soit focalisée sur la fille de Marie-Thérèse qui, durant sept ans, n'arrive pas à enfanter, preuve du caractère stérile et néfaste de l'alliance. Impossible "d'accoupler les lis et l'aigle», pour reprendre la formule d'une chanson écrite à l'occasion de son mariage. Et quand l'Autrichienne finit par avoir des enfants, ce ne sont évidemment pas ceux du roi... On lui attribue, sans la moindre preuve, une multitude d'amants... et d'amantes.

7 Sa jeunesse, sa beauté, sa spontanéité, qui lui avaient valu les applaudissements du petit peuple à son arrivée en France, ne peuvent contrebalancer longtemps la médisance, la rumeur, la calomnie, le flot de boue qui ne fera que s'enfler et devenir un torrent tumultueux emportant tout sur son passage. Les premiers persiflages mondains étaient déjà fort cruels. Témoin, ce fameux pamphlet de 1774 sur le Lever de l'aurore. D'autres suivent, écrits orduriers ou pornographiques : Les amours de Charlot [le comte d'Artois] et de Toinette, La Reine dévoilée, Le Bordel royal, Les Fureurs utérines de MarieAntoinette, tandis qu'un opéra-proverbe de 1789 s'intitule L'Autrichienne en goguette ou l'Orgie royale et un autre Le Godemiché royal...

8 Ainsi se façonne le portrait de ce double extravagant, celui d'une catin lascive, lubrique, nymphomane, lesbienne, perverse, menteuse, criminelle, sanguinaire, panthère couronnée mariée au gros cochon, qui n'a plus rien à voir avec la femme réelle, et qui cristallise les passions haineuses. Elle est la nouvelle Messaline, une Frédégonde, une Isabeau de Bavière, une Catherine de Médicis. Ce dévoiement vertigineux - est-ce étonnant? - se termine par l'insoutenable accusation d'inceste entre elle et son fils proférée par Jacques-René Hébert devant le Tribunal révolutionnaire.

9 Et encore, l'opinion n'a rien su de la correspondance que sa mère échange avec elle, des énormes pressions qu'elle subit de la part de l'ambassadeur Mercy-Argenteau et du chancelier Kaunitz, rien du chantage affectif de son frère, l'empereur Joseph II, ni de sa 
correspondance avec Fersen pendant la Révolution, où elle essaie de faire passer quelques renseignements militaires à l'ennemi !

La reine, il est vrai, prête le flanc à la critique par ses goûts, ses dissipations, ses dépenses, ses moqueries, son mépris des convenances. Elle soutient les intérêts autrichiens contre la France lors de la crise bavaroise de 1778-1779, intervient de manière intempestive au moment de l'affaire des bouches de l'Escaut en 1784. Elle n'hésite pas à presser le roi pour qu'il se débarrasse de certains de ses ministres. On lui impute - à tort sans doute - la disgrâce de Turgot. Elle entre en politique véritablement après le renvoi de Calonne, en 1787, qu'elle provoque, et la crise psychologique grave qui affecte alors le roi. Elle a poussé au renvoi de Necker en juillet $1789 . .$.

11 Annie Duprat insiste avec raison sur le fait que la bergère de Trianon mettra longtemps avant de prendre conscience du danger que représentent les cabales sordides, les pamphlets grivois ou obscènes, les caricatures mortifères. Insouciante, naïve peut-être, elle vit dans un monde isolé. Le réveil sera brutal. En août 1788, elle écrit : «Mon sort est de porter malheur !»

Le deux cent cinquantième anniversaire de la naissance de Marie-Antoinette a donné lieu à une floraison d'ouvrages, sans compter le film, esthétiquement agréable mais historiquement contestable, que lui a consacré Sofia Coppola et qui fait de MarieAntoinette une adolescente branchée dans un monde guindé et suranné. Sur un sujet que l'on pourrait croire épuisé, et sur lequel tant de dévotes fadeurs ont été écrites, Annie Duprat, après les travaux historiques sérieux d'Évelyne Lever et de Simone Bertière, apporte une vision originale et particulièrement intéressante pour l'historien des idées et des mentalités, avec un texte clair et bien écrit. Ainsi la dernière reine de l'Ancien Régime a-t-elle un double corps, comme les rois capétiens que l'on représentait autrefois en effigie une fois morts : mais ce double, au lieu de magnifier la fonction et d'en souligner le caractère inaltérable, est au contraire une sorte de monstre insaisissable et maléfique, vomi des Enfers, "objet d'érotisation extrême ", avec lequel, hélas, elle doit vivre, et qui peu à peu envahit son corps de chair, le happe, le saisit, l'étouffe et finalement le dévore tout entier. Et, c'est peut-être en définitive cet obscur combat entre l'insouciance et la haine, malgré les fautes et les erreurs dont on ne saurait exempter la "reine brisée", qui rend son tragique et fatal destin si émouvant. 